\title{
“E AÍ? COMO VAI A ESCOLA?": UMA REVISÃO SISTEMÁTICA SOBRE O PAPEL DA FORMAÇÃO ESPORTIVA NO PROCESSO DE ESCOLARIZAÇÃO DE ATLETAS ADOLESCENTES
}

\author{
Giovana Rastelli \\ Universidade Federal de Santa Catarina, Florianópolis, Santa Catarina, Brasil. \\ Alexsandra da Silva Bandeira \\ Universidade Federal de Santa Catarina, Florianópolis, Santa Catarina, Brasil.
}

\section{Resumo}

O objetivo deste estudo foi investigar o impacto da formação esportiva na escolarização de atletas adolescentes que cursam a educação básica, através de uma revisão sistemática. Para a busca foram utilizadas as bases de dados Eric (Pro Quest), Lilacs, Scielo, Scopus, Sportdiscus e Web of Science. Foram incluídos artigos originais publicados entre 1998 e 2018, nos idiomas português, inglês e espanhol. Artigos que discutem populações específicas foram excluídos. A busca inicial resultou em 298 estudos e, após o processo previsto pelo fluxograma prisma, restaram oito artigos para fundamentar a discussão. A escola é compreendida como fundamental pelo fato de mobilizar estratégias para a permanência dos atletas na instituição. Pais e professores também possuem responsabilidade no processo.

Palavras-chave: Atletas. Adolescentes. Formação esportiva. Escolarização.

\section{"WHAT'S UP? HOW IS THE SCHOOL GOING? ": A SYSTEMATIC REVIEW ABOUT THE ROLE OF SPORTS TRAINING IN THE SCHOOLING PROCESS OF ADOLESCENT ATHLETES}

\begin{abstract}
The aim of the study was to investigate the impact of sports training on schooling of adolescente athletes who attend basic education, through a systematic review. For the search were used the databases Eric (Pro Quest), Lilacs, Scielo, Scopus, Sportdiscus and Web of Science. Original articles published between 1998 and 2018, in Portuguese, English and Spanish, were included in the collection. Articles discussing specific populations were excluded. The initial search resulted in 298 studies, and after the process predicted by the prism flowchart, there were 8 articles to support the discussion. The school is understood as fundamental role for mobilizing strategies for the permanence of the athletes in the institution, parents and teachers also have responsibility in the process.
\end{abstract}

Keywords: Athletes. Adolescents. Sports training. Schooling. 


\title{
¿Y AHÍ?:CÓMO ESTÁ LA ESCUELA? ": UMA REVISIÓN SISTEMÁTICA DEL PAPEL DE LA FORMACIÓN DEPORTIVA EN EL PROCESO DE ESCOLARIZACIÓN DE ATLETAS ADOLESCENTES
}

\begin{abstract}
Resumen
El objetivo del estudio fue investigar el impacto de la formación deportiva en la escolarización de atletas adolescentes que se encuentran en la educación básica, a partir de una revisión sistemática. Se utilizaron las bases de datos Eric (Pro Quest), Lilacs, Scielo, Scopus, Sportdiscus y Web of Science. Se incluyeron artículos originales publicados entre 1998 y 2018, en portugués, inglés y español. Se excluyeron artículos sobre poblaciones específicas. La búsqueda inicial resultó en 298 estudios, y después del proceso previsto por el diagrama de flujo prisma, quedaron 8 artículos para la discusión. La comprensión de la escuela es fundamental para mantener los atletas estudiando, así como padres y profesores.
\end{abstract}

Palabras clave: Atletas. Adolescentes. Formación deportiva. Escolarización.

\section{Introdução}

A adolescência é uma construção histórico-social marcada por diversas alterações físicas, psicológicas e sociais, e é definida pela World Health Organization (WHO/OMS) (2014) como o período que vai dos 10 aos 19 anos. É nessa fase que costumam emergir preocupações em diferentes contextos e, no que se refere às escolhas pessoais, os jovens muitas vezes se deparam com embates entre seus sonhos e deveres. Em particular, quando seguir a carreira esportiva é o desejo do adolescente, o objetivo acaba envolvendo outros atores ao longo do processo, como familiares e professores.

Com a intenção de favorecer a permanência dos jovens atletas na escola, familiares e professores procuram encontrar maneiras de flexibilizar o processo educacional, tendo em vista que o esporte é um importante instrumento formativo em seus aspectos sociais, psicológicos e de saúde (PESERICO; KRAVCHYCHYN; OLIVEIRA, 2015; AZEVEDO et al., 2017). Todavia, ambas as formações exigem longo tempo de dedicação, o que inevitavelmente favorece a desistência de diversos aspectos da rotina por parte dos adolescentes (MELO, 2010). Além dos momentos de lazer, a dedicação à escola acaba não sendo prioridade, o que possivelmente impulsiona o distanciamento da realidade escolar (ROCHA et al., 2011).

A literatura ainda divide opiniões sobre o efeito da formação esportiva na formação acadêmica (ALAHMED; YUSOF; SHAH, 2016). O estudo de Melo (2010) investigou atletas de futebol residentes do Rio de Janeiro e apontou que a carga horária dedicada ao esporte é praticamente a mesma que eles disponibilizam para frequentar a escola. $\mathrm{O}$ autor informa que, na categoria sub-15, os jovens treinam uma vez por dia em um determinado turno e estudam em outro. Porém, a partir do sub-17, o clube pode optar por alternar os períodos de treino, o que acaba levando os jovens a frequentarem a escola no período noturno. Para além de questões organizacionais e de infraestrutura, esse período torna-se problemático principalmente em relação ao currículo que, na maioria das vezes, desconsidera que o jovem possui outro tipo de atividade durante o dia, colaborando para que haja falta de interesse e possível abandono dos estudantes (MELO, 2010).

Ao investigar a expectativa em relação à formação escolar e formação profissional com estudantes de escolas públicas e particulares do Rio de Janeiro, Costa e Koslinski (2006) concluíram, através das respostas obtidas, que os que frequentam escolas públicas tendem a almejar as carreiras que não dependem de um diploma de curso superior. O caminho mais citado pelos pesquisados foi o esporte, revelando o conceito de que a formação escolar e 
acadêmica não são cruciais para se obter sucesso na carreira esportiva (COSTA; KOSLINSKI, 2006). Entretanto, há aqueles que não conseguem alcançar o sucesso desejado no esporte, então a falta de investimento na formação escolar poderá ocasionar dificuldades numa futura inserção no mercado de trabalho (ROCHA et al., 2011).

Em consonância com a preocupação que percorre a realidade brasileira, os estudos realizados fora do Brasil apontam que há necessidade de políticas públicas que garantam a inserção dos atletas após suas trajetórias esportivas (MELO; SOARES; ROCHA, 2014). A dual carrer (carreira dupla), conforme denominada por Borggrefe e Cachay (2012), faz com que os estudantes-atletas apresentem grandes dificuldades em gerenciar o tempo das atividades esportivas por precisarem cumprir as demandas escolares, o que pode provocar certa desvantagem para algum ou ambos os lados.

Por outro lado, algumas evidências têm apontado que a formação esportiva pode influenciar positivamente aspectos relacionados ao desempenho acadêmico e ao interesse de estudantes-atletas (JORDAN, 1999; WARTENBERG; BORCHERT; BRAND, 2014; GEORGAKIS; EVANS; WARWICK, 2015; ALAHMED; YUSOF; SHAH, 2016). Portanto, a partir do apresentado, e com o objetivo de investigar o impacto da formação esportiva na escolarização de atletas adolescentes que cursam a educação básica, emergiram as questões: quais as relações entre a formação esportiva e o processo de escolarização? Existe algum impacto quando são vividos simultaneamente?

\section{Procedimentos metodológicos}

A investigação é caracterizada como uma revisão sistemática, que pode ser definida como um modelo de pesquisa que utiliza a literatura como fonte de dados (SAMPAIO; MANCINI, 2007). A partir de uma pergunta inicial, a revisão pretende identificar todas as fontes de informação relevantes, reunir e avaliar investigações acerca do tema elencado, com o objetivo de selecionar estudos com qualidade, para que seja possível conduzir uma discussão de maneira eficiente (CORDEIRO et al., 2007; SAUR-AMARAL, 2012).

Para a seleção dos artigos, foi feita uma busca sistematizada nas bases de dados Eric (Pro Quest), Lilacs, Scielo, Scopus, Sportdiscus e Web of Science, em maio de 2018. A partir dos objetivos do estudo, utilizamos os seguintes descritores e operadores boleanos: schooling OR school education AND athlet* OR student-athlete OR adolescent player AND sport*. As pesquisas das bases de dados eletrônicas foram complementadas com uma leitura da lista de referências dos artigos selecionados, a fim de encontrar títulos potencialmente relevantes.

Os critérios de inclusão foram artigos que envolviam o processo de escolarização e de formação esportiva de adolescentes, artigos publicados na íntegra, publicados entre 1998 e 2018 em português, inglês ou espanhol. Foram excluídos artigos de revisão, teses e dissertações, e artigos que discutissem populações específicas, por exemplo, jovens com algum tipo de síndrome.

Inicialmente, a seleção foi baseada na leitura de títulos e resumos dos manuscritos. Após essa etapa, os artigos completos foram obtidos e, posteriormente, analisados de acordo com os critérios de seleção estabelecidos. Foram excluídos os artigos que não atendem a população estabelecida ou não informam as idades; não relacionam esporte e escolarização; não é original; pauta sobre síndrome; escrito em outras línguas; e texto completo indisponível. As listas de referências dos artigos selecionados foram avaliadas. Todas essas etapas foram realizadas de forma independente por dois revisores (AB e GR). As discordâncias em todas as etapas foram discutidas até chegar ao consenso entre as duas autoras.

A extração de dados foi realizada por dois autores (AB e GR), sendo que cada metade das referências foi extraída por um autor e conferida pelo outro. As informações extraídas 
incluíram título, autor, ano, revista, objetivo, método, amostra e resultados. Considerando a heterogeneidade dos estudos, foi adotada uma abordagem narrativa para a descrição dos resultados, apresentados de acordo com o ano de publicação.

\section{Prisma 2018}

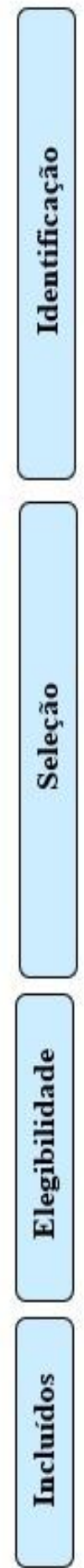

Registros identificados por meio de pesquisa nas bases de dados (298)

- Scopus $=(n=37)$

- Web of Science $=(n=139)$

- $\operatorname{LILACS}=(\mathrm{n}=47)$

- SPORTDISCUS $=(\mathrm{n}=47)$

- SCIELO $=(\mathrm{n}=8)$

- $\operatorname{ERIC}($ PROQUEST $)=(\mathrm{n}=20)$

Registros selecionados para leitura de título e resumo $(\mathrm{n}=280)$

Artigos completos excluídos $(n=13)$

- Não atende a população $(n=4)$

- Não relaciona esporte e escolarização $(\mathrm{n}=2)$

- Não é artigo original ( $\mathrm{n}=1)$

Artigos completos para avaliação da elegibilidade ( $n=19)$ - Aborda sobre síndrome $(\mathrm{n}=1)$

- Outras línguas $(\mathrm{n}=2)$

- Texto completo indisponível ( $\mathrm{n}=2)$

- Não reporta a idade $(\mathrm{n}=1)$

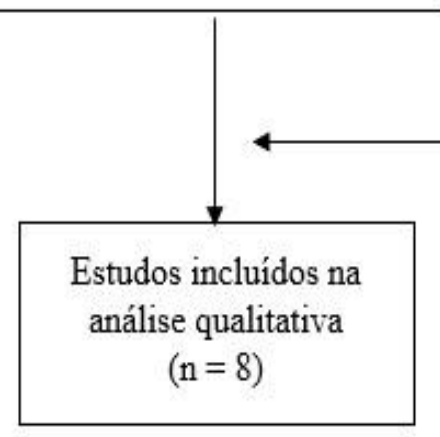

Artigos adicionais identificados

por outras fontes

$(\mathrm{n}=2)$

Figura 1: Resultados do processo de busca de acordo com o fluxograma Prisma. 


\section{Resultados e discussão}

A busca inicial nas bases de dados identificou 298 potenciais estudos (280 títulos após análise de duplicatas). Após a leitura dos títulos e resumos, 261 referências foram excluídas e 19 referências foram encaminhadas para avaliação do texto completo. Ao revisar o conteúdo completo dos artigos, foram excluídas 13 referências (motivos de exclusão detalhados na Figura 1) e seis preencheram os critérios de inclusão. Outras duas referências foram incluídas com base na pesquisa nas listas de referência de estudos. Com isso, oito artigos foram incluídos no presente estudo.

Os oito artigos incluídos foram publicados de 1999 (JORDAN, 1999) a 2017 (O'NEILL; CALDER; HINZ, 2017), sendo que sete deles foram publicados a partir de 2011. Houve maior concentração de estudos publicados na Austrália $(n=4)$, seguida pelo Brasil $(\mathrm{n}=2)$, Alemanha $(\mathrm{n}=1)$ e Estados Unidos $(\mathrm{n}=1)$. Para alcançar o objetivo proposto, os estudos utilizaram tanto métodos qualitativos quanto quantitativos, com diferentes procedimentos metodológicos. Além disso, alguns estudos tiveram amostras compostas somente por adolescentes $(n=6)$, enquanto outros estudos $(n=2)$ incluíram pais e professores. Os resultados referentes à relação entre a formação esportiva e o processo de escolarização serão discutidos a seguir (Quadro 1).

Quadro 1 - Descrição dos estudos e resultados sobre a relação entre formação esportiva e formação escolar.

\begin{tabular}{|c|c|c|c|c|c|c|c|}
\hline TÍTULO & AUTOR & $\begin{array}{l}\text { ANO E } \\
\text { PAÍS }\end{array}$ & REVISTA & OBJETIVO & MÉTODO & AMOSTRA & $\begin{array}{l}\text { RESULTA } \\
\text { DOS }\end{array}$ \\
\hline $\begin{array}{c}\text { Student- } \\
\text { Athletes in } \\
\text { my } \\
\text { Classroom: } \\
\text { Australian } \\
\text { Teachers } \\
\text { Perspectives } \\
\text { of the } \\
\text { Problems } \\
\text { Faced by } \\
\text { Student- } \\
\text { Athletes } \\
\text { Balancing } \\
\text { School } \\
\text { and Sport }\end{array}$ & $\begin{array}{l}\text { O'NEILL } \\
\text {, M.; } \\
\text { CALDE } \\
\text { R, A.; } \\
\text { HINZ, B. }\end{array}$ & $\begin{array}{c}2017 \\
\text { Austrália }\end{array}$ & $\begin{array}{c}\text { Australian } \\
\text { Journal of } \\
\text { Teacher } \\
\text { Education }\end{array}$ & $\begin{array}{l}\text { Examinar a } \\
\text { maneira } \\
\text { como os } \\
\text { professores } \\
\text { apoiam os } \\
\text { jovens para } \\
\text { lidar com } \\
\text { grandes } \\
\text { cargas de } \\
\text { trabalho } \\
\text { físico e } \\
\text { gerenciar os } \\
\text { compromiss } \\
\text { os com a } \\
\text { escola. }\end{array}$ & $\begin{array}{l}\text { Estudo } \\
\text { observacio } \\
\text { nal; } \\
\text { descritivo; } \\
\text { entrevista } \\
\text { semiestrut } \\
\text { urada com } \\
\text { professores } \\
\text { envolvend } \\
\text { o as a } \\
\text { perspectiva } \\
\text { s sobre } \\
\text { alunos- } \\
\text { atletas em } \\
\text { suas aulas } \\
\text { e como } \\
\text { estes se } \\
\text { engajam e } \\
\text { respondem } \\
\text { às } \\
\text { atividades } \\
\text { cotidianas. }\end{array}$ & $\begin{array}{c}10 \\
\text { professores e } \\
19 \text { atletas }\end{array}$ & 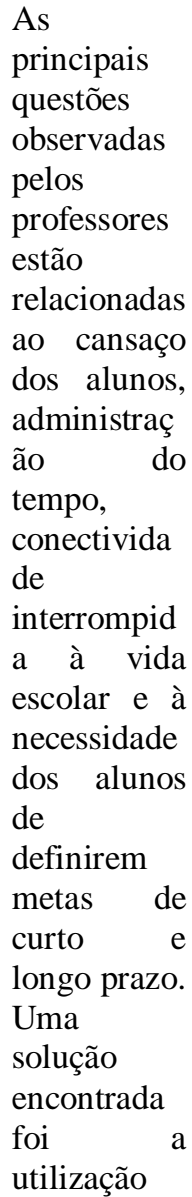 \\
\hline
\end{tabular}




\begin{tabular}{|c|c|c|c|c|c|c|c|}
\hline & & & & & & & $\begin{array}{ll}\text { de recursos } \\
\text { tecnológico } \\
\mathrm{s} \quad \text { para } \\
\text { manter os } \\
\text { atletas } \\
\text { ligados à } \\
\text { escola. }\end{array}$ \\
\hline $\begin{array}{c}\text { Jornada } \\
\text { escolar } \\
\text { versus } \\
\text { tempo de } \\
\text { treinamento: } \\
\text { a } \\
\text { profissionali } \\
\text { zacão no } \\
\text { futebol e a } \\
\text { formação } \\
\text { na escola } \\
\text { básica }\end{array}$ & $\begin{array}{l}\text { MELO, } \\
\text { L. B. S.; } \\
\text { ROCHA, } \\
\text { H. P. A.; } \\
\text { SILVA, } \\
\text { A. L. C.; } \\
\text { SOARES } \\
\text {, A. J. G. }\end{array}$ & $\begin{array}{c}2016 \\
\text { Brasil }\end{array}$ & $\begin{array}{c}\text { Revista } \\
\text { Brasileira } \\
\text { de } \\
\text { Ciências } \\
\text { do Esporte }\end{array}$ & $\begin{array}{l}\text { Analisar o } \\
\text { tempo } \\
\text { dedicado à } \\
\text { formação } \\
\text { profissional } \\
\text { no futebol e } \\
\text { à escola } \\
\text { básica entre } \\
\text { os atletas das } \\
\text { categorias de } \\
\text { base dos } \\
\text { clubes da } \\
\text { cidade do } \\
\text { Rio de } \\
\text { Janeiro e de } \\
\text { fora dela. }\end{array}$ & $\begin{array}{l}\text { Análise } \\
\text { descritiva } \\
\text { com } \\
\text { cálculo de } \\
\text { média e } \\
\text { desvio } \\
\text { padrão } \\
\text { através do } \\
\text { programa } \\
\text { SPSS. }\end{array}$ & $\begin{array}{l}228 \text { atletas } \\
\text { das } \\
\text { categorias } \\
\text { sub-17 e } \\
\text { sub- } 20 \text { de } 19 \\
\text { clubes do } \\
\text { Rio de } \\
\text { Janeiro }\end{array}$ & $\begin{array}{l}\text { Há grande } \\
\text { diferença na } \\
\text { jornada } \\
\text { escolar } \\
\text { entre os } \\
\text { atletas de } \\
\text { clubes da } \\
\text { capital e os } \\
\text { de fora no } \\
\text { sub 17. Os } \\
\text { atletas da } \\
\text { capital têm } \\
\text { o } \\
\text { equivalente } \\
\text { a um dia de } \\
\text { aula } \\
\text { menos na } \\
\text { semana que } \\
\text { os demais. } \\
\text { No sub 20 a } \\
\text { diferença é } \\
\text { menor } \\
\text { (1h49). Os } \\
\text { de fora da } \\
\text { capital estão } \\
\text { distribuídos } \\
\text { quase } \\
\text { igualmente } \\
\text { nos } 3 \text { turnos } \\
\text { escolares, } \\
\text { mas os da } \\
\text { capital } \\
\text { concentram- } \\
\text { se no } \\
\text { vespertino e } \\
\text { noturno. }\end{array}$ \\
\hline $\begin{array}{c}\text { The } \\
\text { Academic } \\
\text { Achievemen } \\
\text { t of Elite } \\
\text { Athletes at } \\
\text { Australian } \\
\text { Schools }\end{array}$ & $\begin{array}{l}\text { GEORG } \\
\text { AKIS, } \\
\text { S.; } \\
\text { EVANS, } \\
\text { J. R.; } \\
\text { WARWI } \\
\text { CK, L. }\end{array}$ & $\begin{array}{c}2015 \\
\text { Austrália }\end{array}$ & $\begin{array}{c}\text { Journal of } \\
\text { Education } \\
\text { and } \\
\text { Training } \\
\text { Studies }\end{array}$ & $\begin{array}{l}\text { Investigar o } \\
\text { desempenho } \\
\text { acadêmico } \\
\text { de atletas de } \\
\text { elite ao } \\
\text { longo de } 11 \\
\text { anos, de } \\
2001 \text { a } 2011 \text {, } \\
\text { comparando- } \\
\text { os com o } \\
\text { desempenho } \\
\text { da } \\
\text { população } \\
\text { geral no } \\
\text { mesmo } \\
\text { período. }\end{array}$ & $\begin{array}{l}\text { Análise } \\
\text { comparativ } \\
\text { a entre } \\
\text { duas } \\
\text { coortes; } \\
\text { Descritiva } \\
\text { e } \\
\text { inferencial } \\
\text { comparand } \\
\text { o níveis de } \\
\text { desempenh } \\
\text { o } \\
\text { acadêmico } \\
\text { (baixo e } \\
\text { alto) entre } \\
\text { atletas de }\end{array}$ & $\begin{array}{c}641 \\
\text { adolescentes }\end{array}$ & $\begin{array}{l}\text { Diferenças } \\
\text { significativ } \\
\text { as (p<0,05) } \\
\text { foram } \\
\text { encontrada } \\
\text { s entre } \\
\text { atletas de } \\
\text { elite e a } \\
\text { população } \\
\text { geral em } \\
\text { três } \\
\text { disciplinas } \\
\text { (Inglês } \\
\text { básico, }\end{array}$ \\
\hline
\end{tabular}




\begin{tabular}{|c|c|c|c|c|c|c|c|}
\hline & & & & & $\begin{array}{l}\text { elite e não- } \\
\text { atletas. }\end{array}$ & & $\begin{array}{l}\text { Matemátic } \\
\text { a geral e } \\
\text { Desenvolvi } \\
\text { mento } \\
\text { Pessoal, } \\
\text { Saúde e } \\
\text { Educação } \\
\text { Física), } \\
\text { sendo que } \\
\text { os atletas } \\
\text { apresentara } \\
\text { m } \\
\text { resultados } \\
\text { melhores. } \\
\text { Três } \\
\text { disciplinas } \\
\text { não } \\
\text { tiveram } \\
\text { resultados } \\
\text { significativ } \\
\text { os (Inglês } \\
\text { Avançado, } \\
\text { Matemátic } \\
\text { a, } \\
\text { Biologia) } \\
\text { entre os } \\
\text { grupos. }\end{array}$ \\
\hline $\begin{array}{l}\text { Australian } \\
\text { Parents } \\
\text { Perception } \\
\text { s of the } \\
\text { Issues } \\
\text { Faced by } \\
\text { their } \\
\text { Adolescen } \\
\text { t High } \\
\text { Performan } \\
\text { ce Sports } \\
\text { Children } \\
\text { in } \\
\text { Balancing } \\
\text { School } \\
\text { and Sport }\end{array}$ & $\begin{array}{c}\text { O'NEILL, } \\
\text { M.; } \\
\text { CALDER, } \\
\text { A.; ALLEN, } \\
\text { B. }\end{array}$ & $\begin{array}{c}2015 \\
\text { Austrál } \\
\text { ia }\end{array}$ & $\begin{array}{c}\text { Journal of } \\
\text { Sports } \\
\text { Pedagogy } \\
\text { and Physical } \\
\text { Education }\end{array}$ & $\begin{array}{l}\text { Explorar os } \\
\text { pontos de } \\
\text { vista de } \\
\text { pais } \\
\text { atletas } \\
\text { sobre as } \\
\text { pressões e } \\
\text { os estresses } \\
\text { que os } \\
\text { atletas de } \\
\text { alto } \\
\text { desempenh } \\
\text { o em idade } \\
\text { escolar } \\
\text { sofrem ao } \\
\text { vivenciar a } \\
\text { vida dupla } \\
\text { de } \\
\text { estudante e } \\
\text { atleta. }\end{array}$ & $\begin{array}{l}\text { Estudo } \\
\text { observacio } \\
\text { nal; } \\
\text { Descritivo; } \\
\text { Entrevista } \\
\text { semiestrutu } \\
\text { rada com } \\
\text { os pais de } \\
\text { atletas } \\
\text { envolvend } \\
\text { o: } \\
\text { percepções } \\
\text { dos pais } \\
\text { sobre o que } \\
\text { seus filhos } \\
\text { vivenciam } \\
\text { ao equilibrar a } \\
\text { vida de } \\
\text { estudante e } \\
\text { atleta. }\end{array}$ & $\begin{array}{c}10 \text { pais } \\
19 \\
\text { atletas }\end{array}$ & $\begin{array}{l}\text { Quando os dados } \\
\text { dos pais foram } \\
\text { comparados com } \\
\text { dados dos atletas } \\
\text { diferenças eram } \\
\text { evidentes: todos } \\
\text { os } 19 \text { atletas, } \\
\text { mas apenas três } \\
\text { pais, relataram } \\
\text { problemas de } \\
\text { gerenciamento } \\
\text { do tempo } \\
\text { relacionados à } \\
\text { vida escolar, } \\
\text { esportiva, } \\
\text { familiar e social. }\end{array}$ \\
\hline $\begin{array}{c}\text { A } \\
\text { longitudin } \\
\text { al } \\
\text { assessmen } \\
\text { t of } \\
\text { adolescent } \\
\text { student- } \\
\text { athletes }\end{array}$ & $\begin{array}{l}\text { WARTENB } \\
\text { ERG, J.; } \\
\text { BORCHER } \\
\text { T, T.; } \\
\text { BRAND, R. }\end{array}$ & $\begin{array}{c}2014 \\
\text { Alema } \\
\text { nha }\end{array}$ & $\begin{array}{c}\text { Sportwissen } \\
\text { schaft }\end{array}$ & $\begin{array}{l}\text { Explorar } \\
\text { empiricame } \\
\text { nte } \\
\text { estudantes- } \\
\text { atletas da } \\
\text { escola de } \\
\text { elite do } \\
\text { esporte }\end{array}$ & $\begin{array}{l}\text { Análise } \\
\text { comparativ } \\
\text { a entre } \\
\text { grupos } \\
\text { Atletas vs. } \\
\text { Desistentes } \\
\text { e Atletas } \\
\text { vs. Não- }\end{array}$ & $\begin{array}{c}260 \\
\text { atletas } \\
(159 \\
\text { meninos } \\
\text { e } 101 \\
\text { meninas } \\
\text { ) }\end{array}$ & $\begin{array}{l}\text { Estudantes- } \\
\text { atletas } \\
\text { matriculados na } \\
\text { EEE tiveram } \\
\text { uma nota média } \\
\text { em matemática } \\
\text { de } 2,27 \text {, } \\
\text { significativament }\end{array}$ \\
\hline
\end{tabular}




\begin{tabular}{|c|c|c|c|c|c|c|c|}
\hline $\begin{array}{c}\text { school } \\
\text { performan } \\
\text { ce }\end{array}$ & & & & $\begin{array}{l}\text { (EEE), } \\
\text { compará- } \\
\text { los com os } \\
\text { de } \\
\text { desistências } \\
\text { do } \\
\text { programa, e } \\
\text { comparar } \\
\text { transversal } \\
\text { mente as } \\
\text { notas } \\
\text { médias dos } \\
\text { alunos- } \\
\text { atletas após } \\
\text { o ensino } \\
\text { médio com } \\
\text { as dos } \\
\text { alunos que } \\
\text { nunca } \\
\text { foram } \\
\text { matriculado } \\
\text { s em uma } \\
\text { EEE. }\end{array}$ & $\begin{array}{l}\text { atletas; } \\
\text { Descritiva } \\
\text { e } \\
\text { inferencial } \\
\text { com } \\
\text { modelos } \\
\text { multiníveis } \\
\text {. }\end{array}$ & & 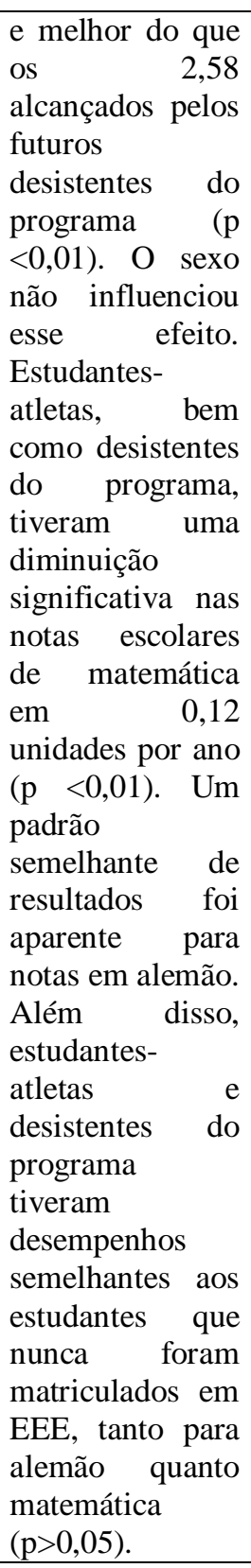 \\
\hline $\begin{array}{l}\text { Pressures } \\
\text { to } \\
\text { perform: } \\
\text { An } \\
\text { interview } \\
\text { study of } \\
\text { Australian } \\
\text { highperfor } \\
\text { mance } \\
\text { school-age } \\
\text { athletes } \\
\text { perception } \\
\text { s of } \\
\text { balancing } \\
\text { theirschoo } \\
\text { l and } \\
\text { sporting } \\
\text { lives }\end{array}$ & $\begin{array}{l}\text { O'NEILL, } \\
\text { M.; } \\
\text { ALLEN, B.; } \\
\text { CALDER, } \\
\text { A. }\end{array}$ & $\begin{array}{c}2013 \\
\text { Austrál } \\
\text { ia }\end{array}$ & $\begin{array}{c}\text { Performance } \\
\text { Enhanceme } \\
\text { nt and } \\
\text { Health }\end{array}$ & $\begin{array}{l}\text { Analisar } \\
\text { como } \\
\text { atletas de } \\
\text { alta } \\
\text { performanc } \\
\text { e em idade } \\
\text { escolar } \\
\text { lidam com } \\
\text { as } \\
\text { demandas } \\
\text { de tempo } \\
\text { integral do } \\
\text { esporte de } \\
\text { alto } \\
\text { rendimento, } \\
\text { trabalhos } \\
\text { escolares e } \\
\text { outras }\end{array}$ & $\begin{array}{l}\text { Estudo } \\
\text { observacio } \\
\text { nal; } \\
\text { Descritivo; } \\
\text { Entrevista } \\
\text { semiestrutu } \\
\text { rada. }\end{array}$ & $\begin{array}{c}19 \\
\text { atletas } \\
\text { de alta } \\
\text { performa } \\
\text { nce }\end{array}$ & $\begin{array}{lr}\text { Os atletas } \\
\text { falaram sobre as } \\
\text { dificuldades de } \\
\text { aprendizagem, o } \\
\text { tempo de aula } \\
\text { perdido, } & \text { a } \\
\text { necessidade de } \\
\text { aulas } \\
\text { individuais, a } \\
\text { importância dos } \\
\text { mentores e a } \\
\text { necessidade de } \\
\text { empatia. Sete } \\
\text { falaram sobre o } \\
\text { tempo de aula } \\
\text { perdido para } \\
\text { participar r de } \\
\text { seus }\end{array}$ \\
\hline
\end{tabular}




\begin{tabular}{|c|c|c|c|c|c|c|c|}
\hline & & & & $\begin{array}{l}\text { questões do } \\
\text { desenvolvi } \\
\text { mento do } \\
\text { adolescente } \\
\text {. }\end{array}$ & & & $\begin{array}{l}\text { compromissos } \\
\text { esportivos. }\end{array}$ \\
\hline $\begin{array}{c}\text { Jovens } \\
\text { Esportistas: } \\
\text { profissionalizaç } \\
\text { ão no futebol e } \\
\text { a formação na } \\
\text { escola }\end{array}$ & $\begin{array}{c}\text { ROCHA, H. } \\
\text { P. A.; } \\
\text { BARTHOL } \\
\text { O, T. L.; } \\
\text { DE MELO, } \\
\text { L. B. S.; } \\
\text { SOARES, } \\
\text { A. J. G. }\end{array}$ & $\begin{array}{c}2011 \\
\text { Brasil }\end{array}$ & Motriz & $\begin{array}{l}\text { Analisar } \\
\text { como os } \\
\text { adolescentes } \\
\text { das } \\
\text { categorias } \\
\text { de base dos } \\
\text { clubes de } \\
\text { futebol do } \\
\text { estado do RJ } \\
\text { conciliam a } \\
\text { formação na } \\
\text { escola } \\
\text { básica com } \\
\text { o futebol e } \\
\text { como os } \\
\text { estudantes- } \\
\text { atletas } \\
\text { percebem o } \\
\text { significado } \\
\text { da escola na } \\
\text { busca por } \\
\text { uma } \\
\text { ocupação. }\end{array}$ & $\begin{array}{l}\text { Estudo } \\
\text { observaciona } \\
\text { 1, descritivo, } \\
\text { guia de } \\
\text { entrevista a } \\
\text { partir de: } \\
\text { formação } \\
\text { profissional, } \\
\text { escolarizaçã } \\
\text { o, história } \\
\text { familiar e } \\
\text { rotina de } \\
\text { vida. }\end{array}$ & $\begin{array}{c}12 \\
\text { atletas de } \\
\text { categoria } \\
\text { s de base } \\
\text { de } 4 \\
\text { clubes }\end{array}$ & $\begin{array}{l}\text { Há } \\
\text { flexibilizaçã } \\
\text { o de } \\
\text { professores } \\
\text { e diretores } \\
\text { para que os } \\
\text { atletas } \\
\text { frequentem } \\
\text { a escola; } \\
\text { escola } \\
\text { dentro do } \\
\text { clube: } \\
\text { facilita em } \\
\text { relação ao } \\
\text { deslocament } \\
\text { o, mas não } \\
\text { tem uma } \\
\text { continuidade } \\
\text { (troca de } \\
\text { professores, } \\
\text { sem horário } \\
\text { e turma } \\
\text { fixa); escola } \\
\text { pública } \\
\text { flexibiliza } \\
\text { mais do que } \\
\text { a particular; } \\
\text { evasão } \\
\text { escolar (3 } \\
\text { atletas) } \\
\text { causada pela } \\
\text { demanda das } \\
\text { duas } \\
\text { atividades, e } \\
\text { eles acabam } \\
\text { optando pelo } \\
\text { futebol; }\end{array}$ \\
\hline $\begin{array}{c}\text { Black High } \\
\text { School } \\
\text { Students' } \\
\text { Participation in } \\
\text { School- } \\
\text { sponsored } \\
\text { Sports } \\
\text { Activities: } \\
\text { Effects on } \\
\text { School } \\
\text { Engagement } \\
\text { and } \\
\text { Achievement }\end{array}$ & $\begin{array}{c}\text { JORDAN, } \\
\text { W. J. }\end{array}$ & $\begin{array}{l}1999 \\
\text { Estado } \\
\text { s } \\
\text { Unido } \\
\text { s }\end{array}$ & $\begin{array}{c}\text { Journal } \\
\text { of Negro } \\
\text { Educatio } \\
n\end{array}$ & $\begin{array}{l}\text { Analisar os } \\
\text { efeitos da } \\
\text { participação } \\
\text { esportiva em } \\
\text { variáveis de } \\
\text { engajamento } \\
\text { escolar e } \\
\text { autoavaliaçã } \\
\text { o de } \\
\text { estudantes, } \\
\text { controlando } \\
\text { característic } \\
\text { as } \\
\text { importantes } \\
\text { como } \\
\text { gênero; } \\
\text { avaliar os }\end{array}$ & $\begin{array}{l}\text { Dados } \\
\text { extraídos do } \\
\text { National } \\
\text { Educational } \\
\text { Longitudinal } \\
\text { Study of } \\
\text { 1988; }\end{array}$ & $\begin{array}{c}17,424 \\
\text { estudante } \\
\text { s }\end{array}$ & $\begin{array}{l}\text { Os } \\
\text { resultados } \\
\text { fornecem } \\
\text { evidências } \\
\text { de que a } \\
\text { participação } \\
\text { em esportes } \\
\text { do ensino } \\
\text { médio está } \\
\text { associada } \\
\text { não apenas } \\
\text { com notas } \\
\text { mais altas, } \\
\text { melhor } \\
\text { autoconceito } \\
\text { e maior } \\
\text { autoconfianç }\end{array}$ \\
\hline
\end{tabular}




\begin{tabular}{|l|l|l|l|l|}
\hline & $\mid \begin{array}{l}\text { potenciais } \\
\text { efeitos da } \\
\text { participação } \\
\text { esportiva de } \\
\text { estudantes } \\
\text { negros; } \\
\text { verificar o } \\
\text { grau em que } \\
\text { a } \\
\text { participação } \\
\text { esportiva } \\
\text { afeta o o } \\
\text { desempenho } \\
\text { acadêmico } \\
\text { dos alunos } \\
\text { negros. }\end{array}$ & \\
mas também \\
com maior \\
desempenho \\
acadêmico \\
entre \\
escolares de \\
diferentes \\
etnias.
\end{tabular}

Fonte: autoras, 2018.

\section{Escola e esporte: formações paralelas ou transversais?}

A relação efetiva entre a rotina do esporte e a escola é contemplada nos estudos de Rocha et al. (2011), ao abordar a flexibilização, a evasão escolar e o papel da escola na visão dos atletas; e O'neill, Allen e Calder (2013) e Melo et al. (2016), com relação à administração do tempo. Os autores pontuaram quão difícil é a conciliação dessas duas formações para os adolescentes. Para além do papel imprescindível na formação de um indivíduo, a escola aparece como um importante mecanismo flexibilizador.

Para que os atletas continuem frequentando a escola, cabe à instituição, através dos diretores e professores, criar estratégias que não dificultem o acesso desses adolescentes, levando em consideração que eles cumprem horários rigorosos de treino, além das diversas viagens para competições (ROCHA et al., 2011). Nesse sentido, o papel da escola é estabelecer metas, manter contato, orientar e acompanhar o desenvolvimento contínuo dos mesmos, também descrito por O'neill, Allen e Calder (2013), que sugerem que o estabelecimento de ensino deve apoiar o atleta por meio de programas.

Ainda em relação à flexibilidade das instituições, existem casos específicos de clubes que possuem escolas dentro das suas acomodações, o que acaba facilitando para os atletas que porventura precisem se deslocar uma longa distância e, dessa forma, conseguem frequentá-la em períodos diferentes de acordo com a rotina de treinos. Porém, essa forma de organização caminha no sentido contrário da lógica brasileira para as escolas básicas, que são estruturadas com turmas e períodos fixos, além de existir uma quebra nos conteúdos ministrados por diferentes docentes (ROCHA et al., 2011).

Apesar de a escola ser fundamental nesse processo, também é papel do estudanteatleta aproveitar as oportunidades que lhe são oferecidas, o que faz com que essa relação necessite de esforços de ambos os lados. O abandono dos estudos faz parte da rotina de muitos atletas por terem que enfrentar o extremo cansaço físico, além das dificuldades de aprendizagem, falta de tempo para o estudo e tempo de aula perdido, o consequente insucesso e posterior falta de motivação, que os faz optarem pelo esporte em detrimento da formação escolar (ROCHA et al., 2011; O’NEILL; ALLEN; CALDER, 2013).

Ao subirem de categoria, o processo de conciliar a rotina de treino com os estudos torna-se um pouco mais simples e em grande parte os atletas optam pelo período noturno para que possam terminar a formação escolar, seja no ensino regular ou supletivo. Frequentar instituições de ensino à noite trazem inúmeros problemas, que vão além de questões 
estruturais e de currículo, como a falta de aulas ocasionada pela ausência de professores (ROCHA et al., 2011; MELO et al. 2016).

A jornada escolar dos adolescentes atletas tornou-se objeto de investigação de Melo et al. (2016), que analisaram a conciliação da rotina somada aos problemas organizacionais das instituições de ensino, por meio de entrevistas com atletas sub-17 e sub-20 de clubes de futebol pertencentes à capital do Rio de Janeiro e de fora dela. Os dados revelaram que há uma diferença na jornada escolar entre os que treinam na capital e os que não treinam.

Em relação aos atletas sub-17 que treinam na capital, os resultados apontaram que eles têm o equivalente a um dia de aula a menos na semana que os demais e que a distribuição ocorre nos períodos vespertino e noturno, enquanto os atletas de fora da capital distribuem-se quase igualmente nos três períodos. Quanto ao sub-20, a diferença não é tão discrepante: os atletas da capital estudam em média uma hora e 49 minutos a menos por semana (MELO et al. 2016). Diversos são os fatores que podem estar relacionados aos resultados encontrados, mas, independente deles, é apropriado elucidar que é responsabilidade do clube acompanhar e dar suporte ao processo de escolarização dos atletas.

A partir do exposto, torna-se visível que, além do próprio atleta, as instituições de ensino e os clubes de treinamento possuem papel importante no processo de escolarização desses jovens. Incluídos nesse movimento, encontram-se também os pais e os professores, responsáveis por acompanhar e auxiliar o andamento de ambas as formações. Em relação ao tema, os dados serão indicados no tópico seguinte.

\section{Professores e pais: a união faz a força?}

A partir do momento em que ampliamos os olhares para os envolvidos na escolarização e nos propusemos a discutir não somente os atores, mas também os agentes desse processo, é que se tornou necessário refletir sobre o papel dos pais e professores ao longo dessa caminhada. Para tanto, nos baseamos nas investigações de O'neill, Calder e Hinz (2017), que se dispuseram a entender como os professores apoiam os adolescentes atletas, e O'neill, Calder e Allen (2015) que exploraram o ponto de vista dos pais e atletas em relação à pressão causada pelo esporte e pela escola.

Os professores são responsáveis ativos na formação de um cidadão e, nesse caso, têm parte do compromisso no que diz respeito à continuidade dos atletas na escola. Os docentes pesquisados apontaram que o que observam com mais frequência sobre esse público diz respeito à condução da conciliação do esporte com a escola e ao cansaço dos alunos devido às altas exigências dos treinos e das demandas escolares. Em decorrência do treinamento e do tempo que passam fora da cidade para participar de competições, os estudantes perdem muitas aulas e, consequentemente, as atividades, o que se torna um fator extra para que os atletas tenham uma carga maior de pressão em relação ao acompanhamento dos conteúdos (O’NEILL; CALDER; HINZ, 2017).

O corpo docente, apoiado pela escola e contando com a participação dos estudantes que se encontram nessa realidade, pode criar soluções para que o atleta se mantenha sempre próximo da instituição. Uma forma de aproximar ainda mais os alunos da escola é utilizar os recursos tecnológicos disponíveis. Os professores entrevistados no estudo de O'neill, Calder e Hinz (2017) deram ênfase aos programas de comunicação como skype, twitter, facebook e outras plataformas on-line, apontando que foram soluções utilizadas por muitos deles para dar continuidade ao processo de escolarização dos atletas, que poderiam se manter conectados enquanto estavam viajando.

A preocupação em manter o vínculo escola-atleta é fundamental para que eles sejam lembrados diariamente que é possível, apesar das dificuldades, construir uma formação 
escolar. Essa tarefa não é responsabilidade apenas da escola e dos professores, mas também dos pais e familiares que acompanham a vida desses atletas, que, certas vezes, podem deixar essa questão de lado por ter que lidar com outros problemas, por exemplo, relacionados a estresse e lesões (O’NEILL; CALDER; ALLEN, 2015).

Pais e atletas entrevistados na pesquisa de O'neill, Calder e Allen (2015) discordaram em relação ao gerenciamento do tempo. O que para todos os atletas foi pontuado como um problema, apenas três pais identificaram como tal. Eles concordaram nas respostas no que diz respeito à pressão sofrida pelos jovens que precisam equilibrar a formação escolar com a esportiva. O resultado da grande demanda posta sobre os estudantes é o crescente estresse físico e psicológico, lesões, overtraining e até mesmo o aparecimento de síndromes, como a

síndrome de Burnout. É dever dos pais se manterem atentos aos sintomas e fornecerem o acompanhamento necessário, porque mesmo demonstrando apoio e acreditando que estão devidamente próximos a essa realidade, muitas vezes eles não sabem o que observar para garantir que seus filhos estejam bem (O’NEILL; CALDER; ALLEN, 2015).

Os pais estão em uma posição privilegiada que permite que eles supervisionem os atletas em diferentes momentos da rotina, e se houver uma ação integrando familiares e professores, o suporte que pode ser oferecido aos adolescentes é ainda maior, resultando num processo de formação escolar e esportiva mais prazeroso e, possivelmente, sem tantos danos.

\section{Desempenho escolar: para além de conceitos}

Além das questões acima relatadas, alguns estudos se propuseram a discutir como o processo de formação esportiva pode estar relacionado ao desempenho acadêmico dos adolescentes. Georgakis, Evans e Warwick (2015) investigaram se o desempenho acadêmico de atletas de elite australianos, ao longo de 11 anos (2001-2011), diferenciava do desempenho de adolescentes pertencentes à população geral, considerando o mesmo período. Para avaliação do desempenho acadêmico, os autores utilizaram as disciplinas de Inglês básico, Inglês avançado, Matemática geral, Matemática, Biologia e Desenvolvimento Pessoal, Saúde e Educação Física. De maneira geral, observamos que atletas de elite apresentaram resultados melhores nas disciplinas de Inglês básico, Matemática geral e Desenvolvimento Pessoal, Saúde e Educação Física quando comparados aos demais estudantes ( $<<0,05)$ (GEORGAKIS; EVANS; WARWICK, 2015). Além disso, não foram observadas diferenças entre os atletas e os demais estudantes para as disciplinas de Inglês Avançado, Matemática, Biologia ( $p>0,05)$.

Em outro cenário, Wartenberg, Borchert e Brand (2014), em um estudo longitudinal, avaliaram estudantes-atletas alemães da Escola de Elite do Esporte (EEE), que, quando comparados aos desistentes desse programa, apresentavam melhores desempenhos em Alemão e Matemática. Também compararam transversalmente as notas médias dos alunosatletas após o ensino médio com as dos alunos que nunca foram matriculados em uma EEE. Em torno de $39 \%$ de alunos-atletas desistiram do programa esportivo ao longo do tempo. Os autores observaram que estudantes matriculados na EEE tiveram uma nota média em matemática de 2,27, significativamente melhor do que os 2,58 alcançados pelos desistentes do programa $(\mathrm{p}<0,01)$. Resultados semelhantes foram encontrados para notas em alemão (WARTENBERG; BORCHERT; BRAND, 2014). Os estudantes-atletas do sexo masculino tiveram nota média de 2,25, melhores que os seus pares desistentes, com nota média de 2,50 ( $p<0,02$ ). Atletas do sexo feminino apresentaram melhor nota em alemão $(1,95)$, quando comparadas às desistentes $(2,20 ; \mathrm{p}<0,01)$. Além disso, estudantes-atletas e desistentes do programa tiveram desempenhos semelhantes aos estudantes que nunca foram matriculados em EEE, tanto para alemão quanto matemática (WARTENBERG; BORCHERT; BRAND, 2014). 
Em um estudo mais antigo, Jordan (1999) avaliou os efeitos da participação esportiva em variáveis de engajamento escolar, autoavaliação e desempenho acadêmico de estudantes, buscando identificar se havia diferença para alunos negros. Foi avaliado o desempenho de 17,424 estudantes nas disciplinas de Leitura, Matemática, História e Ciências, assim como, o autoconceito geral e a autoconfiança acadêmica. Os autores encontraram evidências de que a participação em esportes do ensino médio esteve associada não apenas com notas mais altas, melhor autoconceito e maior autoconfiança acadêmica, mas também com maior desempenho acadêmico entre escolares de diferentes etnias.

A partir do exposto acima, é importante destacar que, apesar da participação esportiva, sendo de alto rendimento ou não, os estudantes ainda são capazes de atingir padrões acadêmicos maiores ou iguais aos não-atletas. Esses resultados indicam que o esporte aparentemente não diminui o tempo, a energia e o comprometimento dos atletas com as atividades acadêmicas, e sim o inverso, melhoram esses aspectos (GEORGAKIS; EVANS; WARWICK, 2015; WARTENBERG; BORCHERT; BRAND, 2014; JORDAN, 1999). Esses achados contribuem para justificar a importância de proporcionar horas necessárias para a prática de esportes e atividades físicas no desenvolvimento curricular dos jovens (JORDAN, 1999).

\section{Considerações finais}

Diante do exposto, percebemos que a escola é concebida como participante ativa da formação escolar dos atletas, principalmente no que se refere às ações flexibilizadoras que a instituição, juntamente ao corpo docente, busca para facilitar o acesso e a permanência desses jovens na realidade em que se encontram. Nesse sentido, os professores também são agentes ativos que possuem a responsabilidade de pensar em estratégias de inserção dos estudantes em suas diferentes realidades, pois todos têm o mesmo direito à educação.

Ao discutir como a formação esportiva pode auxiliar na melhora ou na manutenção de aspectos relacionados ao desempenho acadêmico, bem como o interesse e comprometimento de estudantes atletas, é importante que a inclusão de programas esportivos e a melhoria dos que já existem sejam consideradas na formulação de políticas educacionais. Ainda assim, estratégias para a participação efetiva dos adolescentes nesses programas esportivos podem e devem ser pensadas.

É necessário que a legislação e os documentos que norteiam a educação, e não somente da realidade brasileira, perceba esse estudante atleta como um ator social que não pode depender apenas das ações que a escola disponibiliza, e sim de estratégias legais que garantam a sua formação escolar, ao mesmo tempo em que a formação esportiva progride. Por fim, observamos quão importante se torna a equipe formada por pais e professores, que acompanham o desenvolvimento do atleta no esporte, quando este ainda frequenta o ambiente escolar. Nesse sentido, é fundamental que haja a assistência ao adolescente em diferentes aspectos, como conversas diárias e acompanhamento da rotina.

Apesar de não ser um tema pensado apenas nos últimos anos, notamos que poucos estudos foram publicados sobre o impacto da formação esportiva no processo de escolarização de atletas adolescentes. Em contrapartida, as pesquisas encontradas conseguiram abranger as diferentes perspectivas em relação às formações e aos agentes que estão inseridos nesse processo.

A quantidade de artigos encontrados para a discussão pode ser considerada uma limitação na presente pesquisa, uma vez que foram utilizados poucos descritores nas equações de revisão. Portanto, para uma possível e necessária ampliação, é essencial que a busca contemple um maior número de descritores e de bases de dados. 


\section{Referências}

ALAHMED, M.; YUSOF, A.; SHAH, P. Attitude, sports participation and academic performance of undergraduate student-athletes in Saudi Arabia. Journal of Physical Education and Sport, v. 16, n. 3, p. 1000-1004, 2016.

AZEVEDO, M. F.; SANTOS, W.; COSTA, F. R.; SOARES, A. J. G. Formação escolar e formação esportiva: caminhos apresentados pela produção acadêmica. Movimento, Porto Alegre, v. 23, n. 1, p. 185-200, 2017.

BRASIL. Lei 8.069, de 13 de julho de 1990. Estatuto da Criança e do Adolescente. Brasília, 1990.

BORGGREFE, C.; CACHAY, K. "Dual careers": the structural coupling of elite sport and school. Eur J Sport Soc. 2012.

CORDEIRO, A. M.; OLIVEIRA, G. M.; RENTERÍA, J. M.; GUIMARÃES, C. A. Revisão sistemática: uma revisão narrativa. Revisa do Colégio Brasileiro de Cirurgiões, Rio de Janeiro, v. 34, n. 6, p. 428-431. 2007.

COSTA, M.; KOSLINSKI, M. C. Entre o mérito e a sorte: escola, presente e futuro na visão de estudantes do ensino fundamental do Rio de Janeiro. Revista Brasileira de Educação, Rio de Janeiro, v. 11, n. 31, p. 133-211, 2006.

GEORGAKIS, S.; EVANS, J. R.; WARWICK, L. The Academic Achievement of Elite Athletes at Australian Schools. Journal of Education and Training Studies. v. 3, n. 1, 2015.

JORDAN, W. J. Black High School Students' Participation in School-Sponsored Sports Activities: Effects on School Engagement and Achievement. The Journal of Negro Education, v. 68, n. 1, p. 54-71, 1999.

MELO, L. B. S. Formação e escolarização de jogadores de futebol no Estado do Rio de Janeiro. 2010. 72 f. Dissertação (Mestrado em Educação Física)-Universidade Gama Filho, Rio de Janeiro, 2010.

MELO, L. B. S.; SOARES, A. J. G.; ROCHA, H. P. A. Perfil educacional de atletas em formação no futebol no Estado do Rio de Janeiro. Revista Brasileira de Educação Física e Esporte, São Paulo, v. 28, n. 4, p. 617-628, 2014.

O'NEILL, M.; CALDER, A.; ALLEN, B. Australian Parents Perceptions of the Issues Faced by their Adolescent High Performance Sports Children in Balancing School and Sport. Journal of Sports Pedagogy and Physical Education, v. 6, n. 3, p. 1-12, 2015.

O'NEILL, M. M.; CALDER, A. A.; HINZ, B. Student-Athletes in my Classroom: Australian Teachers Perspectives of the Problems Faced by Student-Athletes Balancing School and Sport. Australian Journal of Teacher Education, v. 42, n. 9, p. 160-178, 2017.

PESERICO, C. S.; KRAVCHYCHYN, C.; OLIVEIRA, A. A. B. Análise da relação entre esporte e desempenho escolar: um estudo de caso. Pensar a Prática, Goiânia, v. 18, n. 2, p. 260-277, 2015.

ROCHA, H. P. A.; BARTHOLO, T. L.; MELO, L. B. S.; SOARES, A. J. G. Jovens esportistas: profissionalização no futebol e a formação na escola. Motriz, Rio Claro, v. 17, n. 2, p. 252-263, 2011.

SAMPAIO, R. F.; MANCINI, M. C. Estudos de revisão sistemática: um guia para síntese criteriosa da evidência científica. Revista Brasileira de Fisioterapia, São Carlos, v. 11, n. 1, p. 83-89. 2007. 
SAUR-AMARAL, I. Revisão sistemática da literatura com apoio de Endnote X5 e NVI-VO 9. Aveiro: QSR, 2012.

WARTENBERG, J.; BORCHERT, T.; BRAND, R. A longitudinal assessment of adolescent studentathletes' school performance: (Not) Worse in school and (not) putting their education at risk?!. Sportwiss. v. 44, n. 78, 2014.

WORLD HEALTH ORGANIZATION (WHO). Adolescent health. 2014. Disponível em: https://www.who.int/maternal_child_adolescent/adolescence/en/. Acesso em: abr. 2018.

Recebido em: 10/09/2018

Revisado em: 30/04/2019

Aprovado em: 21/05/2019

Endereço para correspondência:

giorastelli@hotmail.com

Giovana Rastelli

Universidade Federal de Santa Catarina

Departamento de Educação Física

R. Eng. Agronômico Andrei Cristian Ferreira, s/n

Trindade,

88040-900 - Florianópolis - SC, Brasil. 